\title{
ANALISIS FUNGSI BIAYA STOCHASTIC FRONTIER USAHA PETERNAKAN AYAM PEDAGING PADA PETERNAK YANG MENGGUNAKAN OPEN HOUSE SYSTEM
}

\section{STOCHASTIC FRONTIER COST FUNCTION ANALYSIS OF BROILER BUSINESS FOR OPEN-HOUSE SYSTEM FARMERS}

\author{
Stepanus Pakage $^{a}$. Budi Hartono ${ }^{b}$ Zaenal Fanani ${ }^{b}$, Bambang Ali Nugroho ${ }^{b}$, dan Deny A. Iyai ${ }^{a}$ \\ ${ }^{a}$ Fakultas Peternakan Universitas Papua. Manokwari Papua Barat

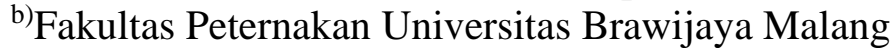

\section{ABSTACT}

Article history

Accepted: May 4, 2018 ;

Approved: June 1, 2018

* Corresponding author:

E-mail:

stpakages@yahoo.com
This study aims to analyze factors that influence the cost function of broiler farms using open house system. The results indicates that all factors included in the model, simultaneously, affect the production costs. Partially, input such as dayold chick (DOC) costs, feed costs, electricity costs, production positively affect the system. Labor costs on the other hand, have a negative effect on the system. The cost of drugs and fuel has no effect on broiler production costs using the open house system.

Keyword: broiler, open house system, cost function, stochastic frontier

\section{PENDAHULUAN}

Peternakan merupakan salah satu bagian dari sektor pertanian yang menghasilkan daging sebagai sumber protein yang sangat penting bagi manusia. Pentingnya daging ayam pedaging tersebut menyebabkan terjadinya peningkatan populasi ternak ayam pedaging di Indonesia. Pada tahun 2016 populasi ayam pedaging mencapai 1.632.568 ribu ekor/head atau meningkat $5 \%$ dari tahun sebelumnya. Produksi daging ayam pedaging pada tahun 2016 adalah sebesar 1.184.366.15 ribu ton atau meningkat $2,8 \%$ dari total produksi daging ayam pada tahun sebelumnya. Menurut Kementerian Pertanian 2016 bahwa konsumsi daging Nasional mencapai 7,75 $\mathrm{kg} / \mathrm{kapita} /$ tahun. Sebanyak 49 persen atau sebanyak 3,80 $\mathrm{kg} / \mathrm{kapita} / \mathrm{tahun}$ konsumsi daging nasional disumbangkan oleh daging ayam. Indonesia dengan jumlah penduduk terbesar keempat di dunia merupakan pasar yang sangat besar, maka permintaan daging ayam pedaging akan meningkat. Data tersebut menunjukkan bahwa ayam pedaging memiliki prospek untuk dikembangkan usahanya.

Usaha peternakan ayam pedaging yang sedang dilakukan di Indonesia adalah dengan pola open house system. Kemampuan peternak ayam pedaging dengan pola open house system dalam mengatasi persoalan lingkungan dan keputusan alokasi sumberdaya tidaklah sama. Hal ini disebabkan karena beragamnya kemampuan peternak, potensi wilayah, dan lingkungan usaha. Perbedaan kemampuan peternak tersebut akan berdampak pada output yang dihasilkan akibat kombinasi penggunaan sejumlah set produksi. Kombinasi penggunaan faktor-faktor produksi pada setiap usaha yang secara efisien adalah syarat mutlak untuk memperoleh keuntungan. Peternak ayam pedaging harus melakukan penghematan agar keuntungan yang diperoleh yang maksimal. Namun sampai sekarang peternak ayam pedaging belum mengetahui apakah faktorfaktor input dalam usaha peternakan ayam pedaging dengan pola open house system 
mempengaruhi biaya produksi. Untuk itu perlu dikaji faktor-faktor yang mempengaruhi fungsi biaya.

\section{MATERI DAN METODE Waktu dan Tempat Penelitian}

Penelitian dilaksanakan di Kabupaten Malang meliputi Kecamatan Pangelaran, Dampit dan Bantur. Pelaksanaan penelitian berlangsung selama 1 bulan terhitung sejak dari 1 Februari sampai dengan 1 Maret 2017.

\section{Metode Pengambilan dan Jumlah Sampel}

Penentuan responden dalam penelitian ini dilakukan secara purposive (sengaja). Pengambilan sampel yang dilakukan adalah dengan cara total sampling yaitu pengambilan sampel secara keseluruhan peternak ayam pedaging dengan pola open house system yang bermitra dengan PT. Sinar Sarana Sentosa.Tbk. Terpilih sebanyak 40 responden yang mengusahakan ayam pedaging dengan pola open house system.

\section{Analisis Fungsi Biaya Usaha Peternakan Ayam Pedaging}

Faktor-faktor yang mempengaruhi fungsi biaya dalam usaha peternakan ayam pedaging dengan pola open house system adalah : biaya bibit ayam (DOC), biaya pakan, biaya medicine, biaya listrik, biaya bahan bakar, biaya tenaga kerja dan produksi. Rumus matematis menurut Coelli dkk, 1998 ., Kumbhakar dan C A K Lovell, 2000 adalah sebagai berikut:

\section{$\operatorname{LnCi}=\alpha 0+\alpha 1 \operatorname{LnW} 1+\alpha 2 \operatorname{LnW} 2+\alpha 3 \operatorname{LnW} 3+\alpha 4 \operatorname{LnW} 4+\alpha 5 \operatorname{LnW} 5+\alpha 6 \operatorname{LnW} 6+\alpha 7 \operatorname{LnY}+\mathrm{Vi}+$ $\mathrm{Ui}$}

Keterangan :

$\mathrm{Ci}=$ Biaya produksi ayam pedaging closed house system per periode produksi $(\mathrm{Rp} / \mathrm{pp})$

$\mathrm{W} 1=$ Biaya bibit ayam pedaging (DOC) per ekor (Rp/ekor)

$\mathrm{W} 2=$ Biaya pakan per kilogram dalam satu periode produksi $(\mathrm{Rp} / \mathrm{kg})$

$\mathrm{W} 3=$ Biaya medicine per unit dalam satu periode produksi (Rp/unit)

$\mathrm{W} 4=$ Biaya listrik yang digunakan per periode produksi $(\mathrm{Rp})$

W5 = Biaya bahan bakar per liter dalam satu periode produksi (Rp/liter)

W6 = Biaya Tenaga kerja yang digunakan per periode produksi (Rp/hari)

$\mathrm{Y}=$ Jumlah produksi ayam pedaging closed house system per periode produksi $(\mathrm{kg} / \mathrm{pp})$

$\alpha 0=$ Konstanta

$\alpha 1-\alpha 6=$ Parameter variabel input yang diduga

Ln $\quad=$ Logaritma Natural e $=2,718$

$\mathrm{Vi} \quad=$ Kesalahan yang dilakukan karena pengambilan secara acak

$\mathrm{Ui}=$ Efek dari efisiensi teknis yang muncul

Pendugaan faktor-faktor yang mempengaruhi fungsi biaya stochastic frontier dilakukan dengan program Frontier versi 4.1c. Pengujian parameter stochastic frontier dilakukan dengan metode Ordinary Least Squares (OLS) dan metode Maximum Likelihood Estimaties (MLE). Pengujian asumsi klasik dilakukan dengan bantuan software Minitab 18.

\section{Uji Signifikansi}

1) Untuk menguji ketepatan model dapat dilketahui dari koefisien determinasi $\left(\mathrm{R}^{2}\right)$. Koefisien determinasi $\left(\mathrm{R}^{2}\right)$ merupakan proporsi keragaman total dari variabel terkait mampu diterangkan oleh variabel bebas. Perhitungan koefisien determinasi $\left(\mathrm{R}^{2}\right)$ adalah sebagai berikut:

$$
\mathrm{R}^{2}=1-\frac{\mathrm{JKS}}{\mathrm{JKT}}
$$

2) Untuk menguji pengaruh variabel bebas terhadap variabel tidak bebas secara bersama-sama (simultan) dilakukan dengan uji $F$. Perhitungan uji $F$ adalah sebagai berikut:

$$
\text { F Hitung }=[\mathrm{JKR} /(\mathrm{k}-1)] /[\mathrm{JKR} /(\mathrm{n}-1)
$$

3) Untuk menganalisis pengaruh masingmasing variabel bebas terhadap variabel 
tidak bebas dilakukan dengan uji t - student. Pengujian $\mathrm{t}$ - student dilakukan dengan rumus:

$$
\text { T Hitung }=b i / S e b i
$$

\section{HASIL DAN PEMBAHASAN}

\section{Uji Multikolinearitas}

Pengujian terhadap multikolinearitas melalui pendekatan fungsi biaya pada usaha peternakan ayam pedaging dengan pola open house system (ohs) dilakukan dengan meregresikan variabel dependen (C) dengan semua variabel independen (Wi). Variabel dependen atau bebas (C) dalam penelitian ini adalah total biaya yang digunakan dalam proses produksi sedangkan variabel independen atau tidak bebas antara lain biaya DOC, biaya pakan, biaya medicine, biaya listrik, biaya bahan bakar, biaya tenaga kerja dan produksi yang dihasilkan.

Berdasarkan pada Tabel 1 bahwa semua variabel independen pada usaha peternakan ayam pedaging dengan pola open house system memiliki nilai Variance Inflation Factor (VIF) yang kurang dari 10. Nilai variance inflation factor yang diperoleh tersebut mengindikasikan bahwa antar variabel independen yang digunakan pada usaha peternakan ayam pedaging dengan pola open house system tidak terjadi korelasi yang tinggi atau sempurna. Hal ini diduga disebabkan karena jumlah yang diobservasi (N) lebih besar dari variabel independen dan juga karena nilai variabel independen yang memiliki variabilitas yang cukup. Dengan demikian estimasi regresi dengan ordinary least square (OLS) akan bersifat BLUE (Best Linear Unbiased Estimator).

\section{Uji Heteroskedastisitas}

Pengujian terhadap heteroskedastisitas dalam penelitian ini bertujuan untuk menguji apakah nilai residual atau error dalam model regresi memiliki variance yang sama (homoskedastisitas). Pendugaan heteroskedastisitas dilakukan dengan uji Glejser. Uji Glejser berkesimpulan bahwa apabila semua koefisien parameter untuk variabel independen tidak signifikan pada taraf kepercayaan $\alpha \quad 0,01$ maka tidak ada heteroskedastisitas. Hasil pengujian heterokedastisitas disajikan pada Tabel 1.

Tabel 1. Hasil Pengujian Multikolinearitas dan Heterokedastisitas Dengan Pendekatan Fungsi Biaya Pada Usaha Peternakan Ayam Pedaging Dengan Pola Open House System.

\begin{tabular}{lccccc}
\hline \multicolumn{1}{c}{ Variabel } & Koefisien & Standart Error & $\mathrm{T}$ & $\mathrm{P}$ & $\mathrm{VIF}$ \\
\hline Constant (W0) & 42513979 & 25179666 & 1,69 & 0,101 & - \\
Biaya DOC (W1) & 1971 & 1616 & 1,22 & 0,231 & 1,514 \\
Biaya Pakan (W2) & -8164 & 4941 & $-1,65$ & 0,108 & 1,346 \\
Biaya Medicine (W3) & 32 & 59,46 & 0,53 & 0,598 & 1,434 \\
Biaya ListriK (W4) & 210 & 1150 & 0,18 & 0,856 & 2,488 \\
Biaya Bahan bakar (W5) & 1225 & 1705 & 0,72 & 0,478 & 2,305 \\
Biaya Tenaga Kerja (W6) & -546 & 388,0 & $-1,41$ & 0,169 & 3,030 \\
Produksi (Y) & 531 & 429,5 & 1,24 & 0,225 & 1,550 \\
\hline
\end{tabular}

Sumber: olahan data primer (2017)

Berdasarkan tabel 1 bahwa variabel biaya bibit ayam / DOC, biaya pakan, biaya medicine, biaya listrik, biaya bahan bakar, biaya tenaga kerja dan produksi pada usaha peternakan ayam pedaging dengan pola open house system tidak berpengaruh pada tingkat kepercayaan $\alpha=0.05$. Nilai $\mathrm{P}$ pada variabel biaya bibit ayam, biaya pakan, biaya medicine, biaya listrik, biaya bahan bakar, biaya tenaga kerja dan produksi pada usaha peternakan ayam pedaging dengan pola open house system melebihi $\alpha=0,05$. Hal ini dapat dilihat pada tabel 1 bahwa pada peternak dengan pola open house system nilai $\mathrm{P}$ berkisar antara 0,101 atau mencapai 10,1\% sampai dengan $0,856(85,6 \%)$. Dengan demikian dapat disimpulkan bahwa nilai 
residual atau error dalam model regresi pada usaha peternakan ayam pedaging dengan pola open house system memiliki variance yang sama atau homoskedastisitas.

\section{Uji Nornalitas Residual}

Pengujian terhadap normalitas residual dengan pendekatan fungsi biaya pada usaha peternakan ayam pedaging dengan pola open house system dilakukan dengan uji Kolmogorov-Smirnov (KS). Hasil pengujian Kolmogorov-Smirnov (KS) disajikan pada Tabel 2 berikut.

Tabel 2. Hasil pengujian normalitas residual dengan fungsi produksi pada usaha peternakan ayam pedaging dengan pola open house system.

\begin{tabular}{|c|c|c|c|c|c|}
\hline \multirow{2}{*}{ Mean } & \multirow{2}{*}{ StDev } & \multirow{2}{*}{$\mathrm{N}$} & \multicolumn{2}{|c|}{ Kolmogorov-Smirnov (KS) } & \multirow{2}{*}{$\mathrm{P}$} \\
\cline { 4 - 5 } & & & Hitung & Tabel & \\
\hline $1.45 \mathrm{E}-02$ & 11872443 & 40 & 0,116 & 0,210 & $>0,150$ \\
\hline
\end{tabular}

Sumber: olahan data primer (2017)

Berdasarkan Tabel 2 bahwa hasil uji Kolmogorov-Smirnov (KS) pada usaha peternakan ayam pedaging dengan pola open house system (ohs) nilai statistik KolmogorovSmirnov (KS) hitung sebesar 0,075 yang mencapai taraf kepercayaan (P-Value) sebesar $15 \%$. Sedangkan nilai statistik KolmogorovSmirnov table untuk $\alpha=0.05 \mathrm{n}=40$ adalah sebesar 0,210. Nilai statistik KolmogorovSmirnov yang diperoleh dari pengamatan $(0,075)$ lebih kecil dari nilai statistik Kolmogorov-Smirnov pada tabel $(0,210)$. Dengan demikian kesimpulan uji kenormalan residual pada fungsi biaya usaha peternakan ayam pedaging dengan pola open house system (ohs) adalah residual model yang dibuat terdistribusi normal.

\section{Analisis Faktor-Faktor Yang Berpengaruh Dalam Fungsi Biaya}

\section{Metode Ordinary Least Squares (OLS)}

Gambaran kinerja rata-rata dalam penggunaan biaya minimum pada tingkat harga tertentu untuk memproduksi sejumlah output tertentu pada usaha peternakan ayam pedaging dengan pola open house system dilakukan dengan metode Ordinary Least Squares (OLS). Hasil estimasi ini digunakan sebagai landasan untuk memperoleh variabel-variabel bebas yang memiliki parameter dugaan konsisten kecuali intersep dan untuk mendapatkan struktur dasar dari fungsi biaya stochastic frontier. Hasil analisis terhadap parameter dugaan fungsi biaya rata-rata dan nilai signifikansinya disajikan pada Tabel 3.

Tabel 3. Hasil Pendugaan Fungsi Produksi dengan Metode Ordinary Least Squares (OLS) pada Peternak Open House System (OHS).

\begin{tabular}{lcccc}
\hline Peubah & Parameter & Koefisien & std-error & t-ratio \\
\hline Konstanta & & 4,8372 & 2,40379 & 2,0123 \\
Biaya Bibit (w1) & $\beta 1$ & 0,3222 & 0,0765 & 4,2115 \\
Biaya Pakan (w2) & $\beta 2$ & 0,3636 & 0,29952 & 1,2139 \\
Biaya Medicine (w3) & $\beta 3$ & 0,0570 & 0,05569 & 1,0235 \\
Biaya Listrik (w4) & $\beta 4$ & 0,1663 & 0,08428 & 1,9737 \\
Biaya B. Bakar (w5) & $\beta 5$ & $-0,0214$ & 0,07817 & $-0,2731$ \\
Biaya T. Kerja (w6) & $\beta 6$ & $-0,3389$ & 0,1129 & $-3,0015$ \\
Produksi (Y) & $\beta 7$ & 1,0297 & 0,05668 & 18,1673 \\
\hline R-Sq(adj) & & 93,6 & \\
F-hitung & & 82,10 & \\
\hline
\end{tabular}

Sumber: Olahan data primer 2017 
Pada Tabel 3 terlihat bahwa fungsi biaya rata-rata yang terbentuk cukup baik (best fit) untuk menggambarkan perilaku peternak didalam meminimumkan biaya produksi. Upaya peternak dalam meminimumkan biaya produksi dapat diketahui melalui nilai koefisien determinasi $\left(\mathrm{R}^{2}\right)$ dan nilai $\mathrm{F}$ hitung. Dalam penelitian ini koefisien determinasi $\left(\mathrm{R}^{2}\right)$ yang diperoleh bernilai 93,6. Nilai tersebut mengandung arti bahwa variabel-variabel yang diikutsertakan dalam model tersebut dapat menjelaskan 93,6 persen dari variasi biaya produksi ayam pedaging. Sedangkan nilai $\mathrm{F}$ hitung yang diperoleh sebesar 82,10. Nilai F hitung tersebut lebih besar dari $\mathrm{F}$ tabel pada $\alpha=$ $0,01_{\mathrm{db}=6}$, dbgalat=44 yakni 3,243033. Hal ini menunjukkan bahwa variabel input seperti harga bibit / DOC (W1), harga pakan (W2), harga medicine (W3), biaya listrik (W4), biaya bahan bakar (W5), biaya tenaga kerja (W6) dan jumlah produksi (Y) secara bersama-sama atau simultan berpengaruh terhadap seluruh biaya produksi ayam pedaging. Dengan demikian bahwa faktor-faktor input tersebut merupakan faktor yang menentukan dalam biaya produksi secara keseluruhan.

\section{Model Empiris Fungsi Biaya Stochastic Frontier}

Pendugaan terhadap model empiris fungsi biaya stochastic frontier pada usaha peternakan ayam pedaging dengan pola open house system dilakukan dengan metode Maximum Likelihood Estimation (MLE). Hasil analisis menggambarkan kinerja terbaik (best practice) dari peternak pada tingkat teknologi yang digunakan. Hasil analisis fungsi biaya stochastic frontier dengan metode maximum likelihood estimation (MLE).disajikan pada Tabel 4.

Tabel 4. Hasil Analisis Fungsi Biaya Stochstic Frontier dengan Metode Maximum Likelihood Estimation (MLE) pada Peternak Open House System (OHS).

\begin{tabular}{lcrrr}
\hline Peubah & Parameter & Koefisien & Std-Error & \multicolumn{1}{c}{ T-Ratio } \\
\hline Konstanta & $\beta 0$ & 336,058 & 0,711177 & 47,254 \\
Biaya Bibit (w1) & $\beta 1$ & 0,29056 & 0,032837 & $8,8485 * * *$ \\
Biaya Pakan (w2) & $\beta 2$ & 0,55737 & 0,106374 & $5,2397 * * *$ \\
Biaya Medicine (w3) & $\beta 3$ & $-0,01975$ & 0,034379 & $-0,5745$ \\
Biaya Listrik (w4) & $\beta 4$ & 0,22779 & 0,014443 & $15,7720 * * *$ \\
Biaya B. Bakar (w5) & $\beta 5$ & $-0,05749$ & 0,065662 & $-0,8756$ \\
Biaya T. Kerja (w6) & $\beta 6$ & $-0,15421$ & 0,051287 & $-3,0068 * * *$ \\
Produksi (Y) & & 0,89883 & 0,052529 & $17,1110 * * *$ \\
\hline
\end{tabular}

Sumber: Olahan data primer 2017

Hasil uji parsial bahwa beberapa variabel yang dimasukkan kedalam model persamaan fungsi biaya usaha peternakan ayam pedaging dengan pola open house system (OHS) memberikan pengaruh yang sangat nyata dan beberapa variabel ditemukan tidak berpengaruh nyata. Variabel-variabel yang mempengaruhi sangat nyata dengan arah positif pada selang kepercayaan $\alpha=0,01_{\mathrm{db}}$ galat 44 adalah variabel biaya bibit ayam /DOC biaya pakan, biaya listrik dan variabel produksi. Sedangkan variabel biaya tenaga kerja ditemukan berpengaruh sangat nyata dengan arah negatif. Variabel-variabel yang ditemukan tidak mempengaruhi biaya produksi total adalah variabel biaya medicine dan variabel biaya bahan bakar. Pembahasan secara terperinci berdasarkan tingkat keberpengaruhan terhadap biaya produksi total ayam pedaging dengan pola open house system adalah sebagai berikut.

Biaya Bibit. Nilai koefisien regresi atau nilai elastisitas biaya yang diperoleh dengan model empiris fungsi biaya stochastic frontier adalah sebesar 0,29056 sedangkan nilai elastisitas biaya yang diperoleh dengan metode Ordinary Least Squres (OLS) adalah sebesar 0.32217 . Nilai koefisien regresi yang diperoleh dengan metode Maximum Likelihood Estimation (MLE) lebih kecil dari pada nilai koefisien regresi yang diperoleh melalui metode Ordinary Least Squres (OLS). Hasil tersebut menunjukkan bahwa peternak ayam 
pedaging dengan pola open house system tidak dapat menambah sejumlah biaya bibit ayam pedaging. Hal ini disebabkan karena biaya variabel bibit sudah melebihi biaya batas (frontier). Penambahan sebesar 10 persen biaya bibit (DOC) ayam pedaging pada kondisi biaya variabel yang lainnya tetap dapat meningkatkan produksi batas (frontier) sebesar 2,9056 persen. Nilai t-hitung yang diperoleh untuk variabel biaya bibit ayam adalah sebesar 8,8485 . Berpedoman pada nilai $\mathrm{t}$-tabel pada selang kepercayaan 99 persen atau $\alpha=0,01_{\mathrm{db}}$ galat 44 yang bernilai 3,243033 bahwa secara statistik variabel biaya bibit ayam berpengaruh sangat nyata terhadap biaya produksi ayam pedaging. Secara teoritis bahwa apabila biaya input-input produksi usaha ternak meningkat maka biaya outputpun harus meningkat. Hal ini sesuai dengan beberapa penelitian dengan obyek ayam pedaging yang telah dilakukan Ismunandar (2012) dan Pakage dkk (2014) bahwa input biaya bibit ayam (DOC) berhubungan positif dengan biaya produksi usaha ternak ayam pedaging.

Biaya Pakan. Peubah biaya pakan yang diestimasi dengan metode Maximum Likelihood Estimation (MLE) diperoleh nilai koefisien regresi sebesar 0,55737 dengan nilai standart deviasi sebesar 0,106374. Nilai koefisien regresi tersebut lebih besar dari nilai koefisien regresi biaya pakan pada fungsi biaya rata-rata yang bernilai 0,36359 dengan standart error sebesar 0.29952. Dengan penambahan biaya pakan sebesar 10 persen pada kondisi variabel yang lainnya tetap dapat meningkatkan seluruh biaya produksi ayam pedaging sebesar 5,5737 persen dari biaya batas (cost frontier). Penggunaan biaya pakan tersebut menunjukkan pengaruh yang sangat nyata terhadap biaya produksi ayam pedaging. Hal ini dapat diketahui melalui nilai t-hitung yang diperoleh adalah sebesar 5,2397. Nilai tersebut lebih besar dari nilai t-tabel pada $\alpha=0,01_{\mathrm{db}}$ galat 44 yang bernilai 2,414134 . Hal ini sesuai dengan yang diharapkan bahwa dengan peningkatan biaya variabel pakan akan diikuti pula oleh peningkatan seluruh biaya produksi ayam pedaging. Penemuan tersebut mengindikasikan bahwa variabel pakan menjadi sangat penting dalam proses produksi ayam pedaging karena produksi ayam pedaging sangat tergantung pada kualitas dan jumlah pakan yang diberikan. Tercapainya aspek biologis, pertumbuhan dan produksi yang maksimum jika kualitas dan kuantitas pakan memadai (Suprijatna, dkk, 2005). Hasil penelitian yang dilakukan oleh Ismunandar (2012) juga menemukan bahwa biaya variabel pakan merupakan faktor yang sangat berpengaruh terhadap total biaya produksi ayam ras pedaging pada peternak di Kota Kendari Sulawesi Tenggara. Oleh karena itu, salah satu input yang paling penting untuk menjadi perhatian peternak ayam pedaging untuk memaksimumkan keuntungan adalah variabel pakan sebab biaya pakan merupakan proporsi terbesar dalam proses produksi .

Biaya Listrik. Variabel biaya listrik yang diperoleh pada biaya rata-rata maupun yang diperoleh melalui model empiris fungsi biaya stochastic frontier berpengaruh sangat nyata pada taraf kepercayaan 99 persen terhadap biaya produksi total. Hal ini dapat ditunjukkan oleh nilai t hitung pada model fungsi biaya stochastic frontier sebesar 15,7720 yang nilai tersebut lebih besar dari t tabel pada $\alpha=0,01_{\mathrm{df}}$ galat 44 yakni sebesar 2,414134. Hasil penelitian ini sesuai dengan harapan bahwa dengan peningkatan biaya listrik maka akan meningkatkan juga biaya produksi secara keseluruhan. Sedangkan berdasarkan besaran nilai koefisien regresi bahwa terjadi peningkatan sebesar 0,06145 antara koefisien regresi yang diperoleh dengan metode ordinary least squares yakni sebesar 0,16634 dan dengan metode Maximum Likelihood Estimation (MLE) sebesar 0,22779. Peningkatan biaya listrik tersebut menunjukkan bahwa pembiayaan variabel listrik pada usaha petenakan ayam pedaging dengan pola open house system masih dapat ditingkatkan untuk mencapai biaya batas (cost frontier) namun dengan berbagai pertimbangan. Dengan demikian peternak ayam pedaging dengan pola ini dapat meningkatkan penggunaan variabel listrik dengan tujuan dapat maksimumkan keuntungan. Biaya variabel listrik yang secara statistik berpengaruh sangat nyata terhadap biaya produksi total mengindikasikan bahwa variabel tersebut menjadi sangat penting dalam proses produksi. Hal ini sejalan dengan hasil penelitian Pakage dkk, 2015 bahwa listrik 
berpengaruh terhadap produksi ayam pedaging.

Produksi. Faktor yang juga mempengaruhi fungsi biaya usaha peternakan ayam pedaging dengan pola open house system adalah faktor produksi ayam pedaging. Hasil penelitian menunjukkan bahwa variabel produksi yang diperoleh pada biaya rata-rata maupun yang diperoleh melalui model empiris fungsi biaya stochastic frontier berpengaruh sangat nyata pada taraf kepercayaan 99 persen terhadap biaya produksi keseluruhan. Hal ini dapat dilihat dari nilai t hitung pada model OLS yakni sebesar 18,1673 dan pada model MLE adalah 17,1110 yang kedua nilai tersebut lebih besar dari nilai t tabel pada selang kepercayaan $\alpha=0,01$ df galat 44 yakni 2,414134. Pada pendugaan dengan metode ordinary least squares koefisien regresi bertanda positif dengan nilai 1,02969 dan nilai koefisien regresi pada metode Maximum Likelihood Estimation (MLE) sebesar 0,89883. Dengan penambahan sebesar 10 persen produksi ayam pedaging maka biaya produksi akan meningkat sebesar 8,9883 persen. Nilai koefisien regresi variabel produksi yang diperoleh tersebut menempati urutan pertama nilai koefisien tertinggi bila dibandingkan dengan nilai koefisien biaya variabel lainnya.Demikian juga nilai $t$ hitung bahwa koefisien regresi variabel produksi memiliki nilai tertinggi bila dibandingkan dengan nilai t hitung biaya variabel lainnya yang dimasukkan kedalam model. Secara statistik variabel produksi ayam yang berpengaruh sangat nyata tersebut diduga disebabkan karena besarnya jumlah produksi ayam yang dihasilkan dipengaruhi oleh besarnya jumlah faktor-faktor produksi (masukkan) yang tentunya jumlah faktor-faktor produksi tersebut dipengaruhi juga oleh biaya masing-masing variabel. Dengan kata lain bahwa gambaran kinerja rata-rata dan variasi proporsi masukkan untuk menghasilkan sejumlah hasil produksi secara fisik dipengaruhi oleh jumlah produksi dan secara nilai (value) digambarkan oleh biaya produksi.

Biaya Tenaga Kerja. Salah satu variabel yang diikutsertakan dalam model pada fungsi biaya usaha peternakan ayam pedaging dengan pola open house sistem yang secara statistik berpengaruh sangat nyata pada taraf kepercayaan 99 persen dengan arah yang negatif terhadap biaya produksi total adalah variabel biaya tenaga kerja. Hal ini ditunjukkan oleh nilai t-hitung yang diperoleh yakni -3.0015 dengan metode OLS dan -3,0068 dengan metode MLE. Nilai koefisien regresi biaya peubah tenaga kerja yang diperoleh pada model empiris fungsi biaya stochastic frontier adalah sebesar -0,15421. Nilai koefisien regresi tersebut sama dengan dari nilai koefisien regresi yang diperoleh dengan metode Ordinary Least Squres (OLS) yakni sebesar 0,15421 . Keputusan akan menambah biaya variabel tenaga kerja merupakan pertimbangan khusus bagi peternak ayam pedaging dengan open house system guna memaksimumkan keuntungan. Kondisi demikian menunjukkan bahwa tingkat penggunaan biaya variabel tenaga kerja sudah mencapai biaya maksimum (cost frontier). Penemuan dalam penelitian ini tidak sesuai dengan harapan bahwa dengan penambahan sejumlah biaya tenaga kerja akan meningkatkan juga biaya produksi total. Dengan penambahan biaya variabel tenaga kerja akan menambah biaya secara keseluruhan dimana variabel tenaga kerja tidak berpengaruh terhadap produksi. Hasil temuan ini mendukung hasil penelitian yang dilakukan Ismunandar (2012) bahwa peubah tenaga kerja dengan satuan pengukuran hari kerja setara pria (HKSP) tidak mempengaruhi produksi ayam pedaging pada taraf kepercayaan $\alpha=0,05$ di Kota Kendari.

Biaya Medicine. Pada fungsi biaya ratarata yang dianalisis dengan metode ordinary least squares (OLS) bahwa nilai koefisien regresi variabel biaya medicine yang diperoleh adalah sebesar 0,05700 dengan nilai standart error sebesar 0,05569 sedangkan dengan model empiris fungsi biaya stochastic frontier yang dianalisis dengan metode Maximum Likelihood Estimation (MLE) diperoleh nilai koefisien regresi variabel biaya medicine 0,01975 dengan standart error sebesar 0,034379 . Berdasarkan nilai koefisien regresi tersebut bahwa terjadi perubahan arah pada fungsi biaya rata-rata yang positif menjadi arah negatif pada model empiris fungsi biaya stochastic frontier. Perubahan arah nilai koefisien regresi variabel biaya medicine tersebut mengindikasikan bahwa biaya variabel medicine secara statistik tidak akan mempengaruhi keseluruhan biaya produksi. 
Dengan penambahan sejumlah 10 persen biaya medicine akan meningkatkan biaya produksi ayam pedaging sebesar $-0,1975$ persen namun kenaikan tersebut tidak berpengaruh terhadap total biaya produksi. Berdasarkan nilai t-hitung yang diperoleh sebesar $-0,5745$ bahwa variabel biaya medicine tidak berpengaruh terhadap seluruh biaya produksi ayam pedaging. Hasil uji statistik tersebut menjadi pedoman bagi peternak ayam ras pedaging dengan pola closed house system dalam proses pengambilan keputusan terhadap penggunaan variabel medicine guna memaksimumkan keuntungan. Hasil penelitian Ismundar (2012) bahwa harga variabel vitamin berpengaruh negatif pada taraf kepercayaan 99 persen dan harga variabel vaksin dan obat tidak mempengaruhi biaya produksi ayam ras pedaging. Penemuan dalam penelitian ini menunjukkan bahwa secara statistik variabel biaya medicine tidak berperan dalam proses produksi ayam pedaging walaupun dalam proses variabel medicine diperlukan untuk upaya pencegahan dan pengobatan serta dalam memacu pertumbuhan ayam pedaging.

Biaya Bahan Bakar. Salah satu variabel yang juga digunakan dalam proses produksi usaha peternakan ayam pedaging dengan pola open house system adalah bahan bakar. Variabel bahan bakar digunakan peternak pada saat masa brooding. Pemanasan tersebut menjadi sangat penting untuk meransang pertumbuhan ayam. Biaya atas variabel tersebut dipengaruhi oleh harga berlaku pada saat proses produksi berlangsung. Berdasarkan uji statistik bahwa variabel biaya bahan bakar pada usaha dengan pola open house system tidak berpengaruh nyata terhadap seluruh biaya produksi. Hal ini dapat dilihat dari nilai t-hitung yang diperoleh yakni sebesar -0,8756 yang nilai tersebut lebih kecil dari nilai t-tabel pada taraf kepercayaan 95 persen dengan derajat bebas galat sebanyak 48 yakni 1,680230. Nilai koefisien regresi biaya bahan bakar adalah sebesar -0,05749. Nilai koefisien regresi biaya bahan bakar tersebut mengartikan bahwa dengan kenaikan biaya bahan bakar sebesar 10 persen pada kondisi biaya variabel lainnya tetap akan meningkatkan biaya produksi ayam pedaging sebesar $-0,5749$ persen. Oleh karena kenaikan biaya variabel bahan bakar yang sangat kecil maka variabel tersebut tidak ada pengaruh terhadap biaya produksi total. Hasil penelitian ini sama dengan hasil penelitian yang dilakukan oleh Ismunandar (2012) bahwa variabel biaya brooding tidak berpengaruh terhadap biaya produksi. Hasil pada penelitian ini sesuai dengan yang diharapkan bahwa dengan kenaikan biaya variabel bahan bakar akan meningkatkan juga biaya produksi. Kesamaan hasil yang ditemukan pada penelitian ini dengan penelitian Ismunandar, 2012 diduga disebabkan karena adanya kesamaan dalam jumlah dan biaya per satuan bahan bakar.

\section{Analisis Variance dan Parameter $\gamma$ Model Efek Inefisiensi biaya pada Fungsi biaya Stochastic Frontier}

Pada usaha peternakan ayam pedaging dengan pola open house system nilai sigma squared $\left(\sigma^{2}\right)$ yang diperoleh adalah sebesar 0,00703. Nilai sigma squared tersebut menunjukkan bahwa adanya keragaman biaya produksi ayam pedaging dengan pola open house system yang disebabkan oleh adanya efisiensi ekonomi atau dengan kata lain bahwa sebesar 0,002895 persen keragaman biaya produksi disebabkan oleh faktor-faktor inefisiensi ekonomi. 
Tabel 5. Varians dan parameter $\gamma$ dari model efek inefisiensi ekonomi fungsi biaya stochastic frontier pada Peternak Open House System (OHS).

\begin{tabular}{llll}
\hline \multicolumn{1}{c}{ Komponen } & Koefisien & \multicolumn{1}{c}{ Std-Error } & \multicolumn{1}{c}{ T-hitung } \\
\hline Sigma-squared $(\sigma 2=\sigma 2 \mathrm{v}+\sigma 2 \mathrm{u})$ & 0,00703 & 0,0022844 & $3,077 * * *$ \\
Gamma $(\gamma=\sigma 2 \mathrm{u} / \sigma 2 \mathrm{v}+\sigma 2 \mathrm{u})$ & 0,99999 & 0,0092787 & $107,774 * * *$ \\
\hline Log Likelihood & & & 68,443 \\
LR Test & & & 30,516 \\
\hline
\end{tabular}

Sumber: Olahan data primer 2017

Pada Tabel 5 tampak bahwa nilai gamma $(\gamma)$ yang diperoleh pada usaha peternakan ayam pedaging dengan pola open house system adalah sebesar 0,9999. Angka ini menunjukkan bahwa variasi kesalahan pengganggu yang disebabkan efisiensi ekonomi adalah sebesar 99,99 persen atau perbedaan antara biaya produksi yang sesungguhnya dengan kemungkinan biaya produksi maksimum antar peternak sebesar 99,99 persen disebabkan karena perbedaan efisiensi ekonomi dan sebesar 0,11 persen disebabkan oleh efek-efek stochastic seperti kesalahan pengukuran. Hasil analisis terhadap parameter $\gamma$ yang merupakan rasio dari varians efisiensi teknis $(\mu \mathrm{i})$ terhadap varians total produksi ( $\varepsilon i)$ pada kedua kelompok peternak ditemukan berpengaruh sangat nyata pada taraf kepercayaan $\alpha=0,01$. Nilai gamma $(\gamma)$ yang hampir mendekati 1 pada usaha peternakan ayam pedaging open house system tersebut menandakan bahwa galat satu sisi (one-sided error) $\mathrm{u}_{\mathrm{i}}$ mendominasi sebaran galat simetris dari vi (Schmidt and C A K Lovell. 1979). Hal ini juga didukung oleh perolehan nilai LR test of one-sided error yang sangat nyata. Nilai LR test yang diperoleh peternakan ayam pedaging dengan pola open house system adalah sebesar 30,516. Nilai LR test yang diperoleh tersebut jauh lebih besar dari nilai $\chi^{2}=3,84146$. Hasil penelitian ini sama dengan penelitian yang dilakukan oleh Udoh dan N A Etim, 2009 pada peternak ayam pedaging di Uyo Akwa Ibom State Nigeria. Ini menunjukkan bahwa hampir semua variasi dalam keluaran dari produksi frontier dapat dianggap sebagai akibat dari tingkat pencapaian efisiensi biaya yang berkaitan dengan persoalan manajerial dalam pengelolaan usaha peternakan ayam pedaging. Hasil penelitian yang dilakukan oleh Ismunandar, (2012) pada peternak ayam pedaging di Kota Kendari memperoleh nilai gamma pada fungsi biaya sebesar 0,618 dan hasil penelitian Ogundari dkk, 2006 ; Todsadee dkk, 2012 dan juga memperoleh nilai gamma pada fungsi biaya sebesar yang lebih besar dari 0,800 .

\section{KESIMPULAN}

Hasil penelitian menunjukkan bahwa seluruh faktor yang dimasukkan dalam model secara bersama-sama (simultan) mempengaruhi biaya produksi ayam pedaging dengan pola open house system. Secara parsial/terpisah faktor biaya bibit (DOC), biaya pakan, biaya listrik, produksi berpengaruh positif dan biaya tenaga kerja ditemukan berpengaruh negatif, sedangkan biaya medicine dan biaya bahan bakar ditemukan tidak berpengaruh terhadap biaya produksi ayam pedaging dengan pola open house system.

\section{DAFTAR PUSTAKA}

Coelli T, Prasada R and G E Battese. 1998. An introduction to efficiency and productivity analysis. Kluwer academic publishers, Boston.

Ismunandar. D. 2012. Analisis Efisiensi Ekonomi Stochastic Frontier Pada Usaha Ternak Ayam Ras Pedaging Di Kota Kendari Propinsi Sulawesi Tenggara. Tesis Magister. Program Pascasarjana Fakultas Peternakan Universitas Brawijaya. Malang.

Kumbhakar S C and C A K Lovell. 2000. Stochastic frontier analysis: an econometric approach. Cambridge university press, Cambridge.

Ogundari K, S O Ojo and I A Ajibefun. 2006. Economies of Scale and Cost Efficiency in 
Small Scale Maize Production: Empirical Evidence from Nigeria J. Soc. Sci., 13(2) p 131-136.

Pakage S., B. Hartono., Z. Fanani and B. A. Nugroho. 2014. Analysis of Technical Efficiency of Poultry Broiler Business with Pattern Closed House System in Malang East Java Indonesia. Journal of Economics and Sustainable Development Vol.5, No.12 p.16-22.

Pakage S., B. Hartono., Z. Fanani and B. A. Nugroho. 2015. Analysis of technical, allocative and economic efficiency of broiler production using closed house system in Malang District of East Java Indonesia. Livestock Research for Rural Development 27 (9).
Schmidt P and C A K Lovell. 1979. Estimating technical and allocative inefficiency retative to stochastic production and cost frontiers. Journal of econometrics, 19(3): $343-366$.

Suprijatna E., Umiyati A., Ruhyat K. 2005. Ilmu Dasar Ternak Unggas. Penebar Swadaya. Jakarta.

Todsadee A, Hiroshi K, Kamol N and Koh-en Y. 2012. Production Efficiency of Broiler Farming in Thailand: A Stochastic Frontier Approach. Journal of Agricultural Science; Vol. 4, No. 12 p 221-231.

Udoh E J and N A Etim. 2009. Measurement of Farm Level Efficiency of Broiler Production In Uyo Akwa Ibom State Nigeria. World Journal Of Agricultures Sciences 5 (s):832-836 